\title{
Decomposition Studies of Solid Residues from Dried Salt Soltuions Containing Phenylborate Compounds
}

by

F. F. Fondeur

Westinghouse Savannah River Company

Savannah River Site

Aiken, South Carolina 29808

DOE Contract No. DE-AC09-96SR18500

This paper was prepared in connection with work done under the above contract number with the U.S. Department of Energy. By acceptance of this paper, the publisher and/or recipient acknowledges the U.S. Government's right to retain a nonexclusive, royalty-free license in and to any copyright covering this paper, along with the right to reproduce and to authorize others to reproduce all or part of the copyrighted paper. 


\section{DISCLAIMER}

This report was prepared as an account of work sponsored by an agency of the United States Government. Neither the United States Government nor any agency thereof, nor any of their employees, makes any warranty, express or implied, or assumes any legal liability or responsibility for the accuracy, completeness, or usefulness of any information, apparatus, product, or process disclosed, or represents that its use would not infringe privately owned rights. Reference herein to any specific commercial product, process, or service by trade name, trademark, manufacturer, or otherwise does not necessarily constitute or imply its endorsement, recommendation, or favoring by the United States Government or any agency thereof. The views and opiniotns of authors expressed herein do not necessarily state or reflect those of the United States Government or any agency thereof.

This report has been reproduced directly from the best available copy.

Available to DOE and DOE contractors from the Office of Scientific and Technical Information, P. O. Box 62, Oak Ridge, TN 37831; prices available from (423) 576-8401.

Available to the public from the National Technical Information Service, U. S. Department of Commerce, 5285.Port Royal Road, Springfield, VA 22161. 


\section{DISCLAIMER}

Portions of this document may be illegible in electronic image products. Images are produced from the best available original document. 
WSRC-TR-99-00023

keywords: Benzene, Thermal Analysis

retention: Permanent

Decomposition studies of Solid Residues from Dried salt

Solutions Containing Phenylborate Compounds

F. F. Fondeur

January 6, 1999

Westinghouse Savannah River Company

Savannah River Site

Aiken, SC 29808

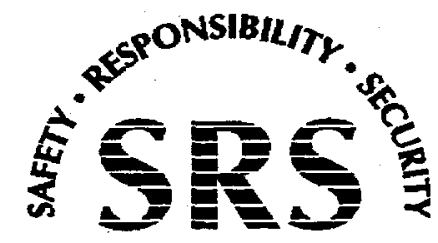


Decomposition Studies of Phenylborate Compounds

\section{Author}

F. F. Fondeur, Waste Processing Technology

Date

Design Check

R. A. Peterson, Waste Processing Technology

Date

Approvals

S. D. Fink, Level 4 Manager

Date Waste Processing Technology 


\section{CONTENTS}

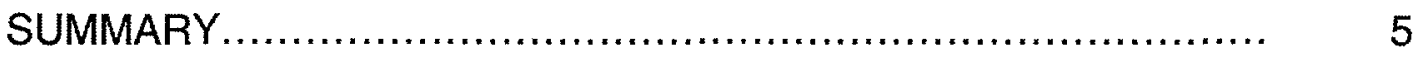

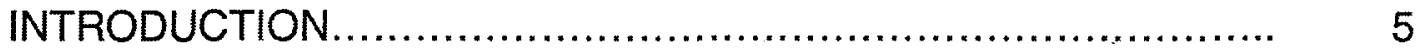

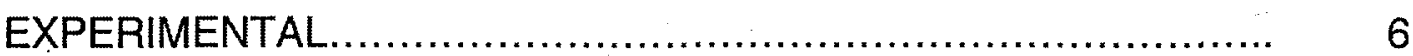

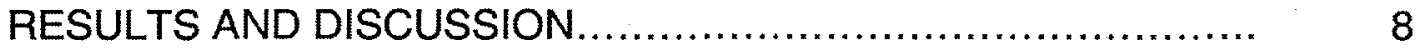

PHENYLBORATE DECOMPOSITION......................... 8

DECOMPOSITION RATE.................................... 10

CONCLUSION...................................................... 12

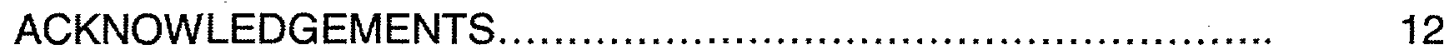

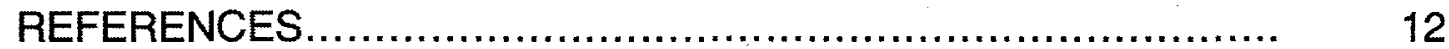

APPENDIX 1: Kinetic Calculations..................................... 14

APPENDIX 2: Rate of Decomposition Calculations.................... 17

APPENDIX 3: Benzene Yields Calculations............................ 18

APPENDIX 4: Uncertainties Calculations of the Rate Constants....... 20 


\section{LIST OF TABLES}

December 1995, Tank 48H Composition.

$3 \quad$ Kinetic Parameters of Phenylborate Decomposition................. 10

4. Weight \% Loss of Solids per mass of Dried Salts per year........... ' 11

$5 \quad$ Fraction of Solids Lost per Phenylborate Compound per day........ 11

$6 \quad$ Kinetic Parameters of Phenylboronic Acid Decomposition............ 16

$7 \quad$ Uncertainties of the Rate Constants Calculations...................... 20

\section{LIST OF FIGURES}

DSC Curve of Phenylboronic acid (1PB) in Dried Solids.

DSC Curve of Diphenylborinic acid (2PB) in Dried Solids........... 22

$3 \quad$ DSC Curve of Triphenylborane (3PB) in Dried Solids............... 23

4 DSC Curve of a Salt Solution Containing all Four Phenylborate Compounds.

5 TGA Curve of Phenylboronic Acid in Dried Solids.

8 TGA Curve of a Salt Solution Containing all Four Phenylborate Compounds........................................................... 28

$9 \quad$ Kinetic Curve from TGA Curve of Phenylboronic Acid (1PB)........ 29

10 Kinetic Curve from TGA Curve of Diphenylborinic Acid (2PB)...... 30

11 Kinetic Curve from TGA Curve of Triphenylborane (3PB)............ 31

12 Kinetic Curve from TGA Curve of a Salt Solution Containing All Four Phenylborate Compounds. The Data is from The Sodium Tetraphenylborate Decomposition.

13 Benzene Production Rate from Dried Solids as a Function .of Temperature. 


\title{
Decomposition Studies of Solid Residues from Dried Salt solutions Containing Phenylborate Compounds
}

\author{
F. F. Fondeur \\ Waste Processing Technology Section \\ Savannah River Technology Center \\ Westinghouse Savannah River Company
}

\section{Summary}

This study determined the decomposition rate of dried solid residues from alkaline salt solutions containing various phenylborate species. Rate determinations come from kinetic analysis of thermal gravimetric measurements made at elevated temperatures. The material tested simulates the liquid content of Tank $48 \mathrm{H}$ during the period of October 1995 through December 1996. The rates allow prediction of benzene formation rates for containers of job control wastes from the In-Tank Precipitation facility. The conclusions from the experimental data indicate the following.

- Kinetic results indicate similar rates of decomposition for triphenylborane and diphenylborinic acid. Their rates exceed that of phenylboronic acid which in turn exceeds that of sodium tetraphenylborate.

- This work suggests a maximum generation rate expected for solid waste from Tank $48 \mathrm{H}$ on November 21, 1995 of 14,141 $\mu \mathrm{g}$ benzene per liter of contained solution per day. Tables, figures, and rate expressions within the report allow prediction of wastes collected at different times from the facility.

- Decomposition rates calculated for wastes at ambient temperatures $\left(\sim 20-25^{\circ} \mathrm{C}\right)$ agree reasonably well with previous measurements for dried sodium tetraphenylborate powder stored at a vendor location.

\section{Introduction}

The Savannah River Site stores various wastes classified as hazardous, non-hazardous, radioactive or mixed. Personnel store non-hazardous waste, often called solid waste, in containers designated as 'B-25s'. Recently, such wastes from the In-Tank Precipitation facility and specifically from Tank $48 \mathrm{H}$ contained relatively large amounts of tetraphenylborate and its decomposition products. Further reaction of the dried waste in the bins could produce benzene leading to potentially flammable conditions in the containers. Solid Waste Engineering requested that the Savannah River Technology Center provide information on the likely decomposition rates for the phenylborate bearing waste [1].

Previous studies on decomposition of vendor supplied sodium tetraphenylborate [2-4] measured the decomposition rate as approximately 1 wt 8 annually. Similarly, previous work by Bibler examined leaching of wastes containing both sodium and potassium tetraphenylborate showing that the resulting leachate would likely contain less than the hazardous amount of benzene (i.e., <0.5 mg/L) [5]. While the rate for vendor 
supplied material and the leaching provides insight into expected benzene formation in waste from ITP, the data does not well represent the conditions of the facility. By December of 1995, the contents of Tank $48 \mathrm{H}$ experienced a rapid reaction that consumed the entire excess amount of sodium tetraphenylborate [6]. This reaction, catalyzed by the palladium and copper present in the solution, formed large

concentrations of triphenylborane (3PB), diphenylborinic acid (2PB) and phenylboronic acid (1PB). The earlier tests lacked the presence of the intermediate decomposition compounds. The current study measured the decomposition rates for more representative alkaline solutions containing the phenylborate compounds by use of calorimetric methods.

\section{Experimental}

The studies used simulated Tank $48 \mathrm{H}$ supernate prepared with the inorganic salt composition shown in Table 1 [7].

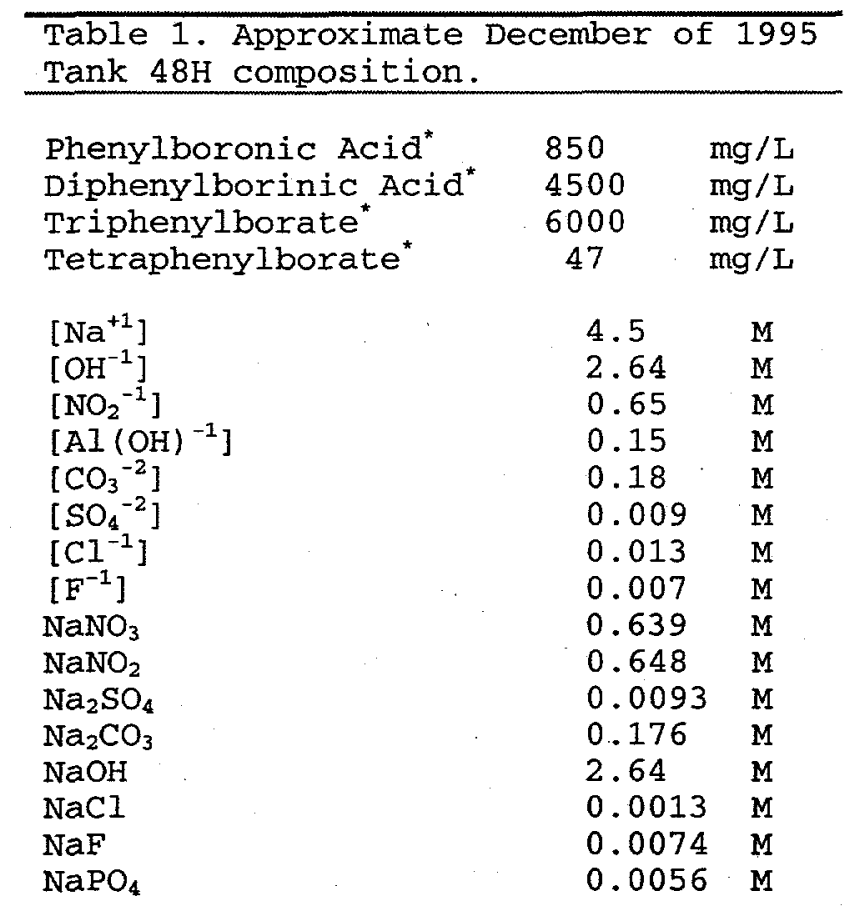

"The listed values represent the maximum amount of the respective compound estimated present at any time during December of 1995. The species did not reach their maximal concentrations on the same dates.

Strongly basic solution stabilizes the tetraphenylborate in the absence of catalytic metals [8]. Researchers diligently excluded copper adducts and palladium, minimized light exposure and maintained low temperatures as these variables can promote phenylborate decomposition in solutions [9-12]. Personnel dried the samples at room temperature for several days until solids of nearly constant weight resulted. Sample preparation included grinding the resulting solids using a spatula with minimum amount of mixing to avoid overheating of sample and therefore, decomposition. The author placed about $10 \mathrm{mg}$ of ground sample in TGA (thermogravimetric analysis) platinum pans and put in the DuPont 2100 thermal analysis equipment. The sample was heated up to $500{ }^{\circ} \mathrm{C}$ at a rate of $10^{\circ} \mathrm{C} / \mathrm{min}$ in an air atmosphere. The analysis can detect $0.01 \mathrm{mg}$, or 
0.18 , weight loss. Weight loss appears as reversed "S letter" shape in the weight loss versus temperature graphs (e.g., see Figure 7).

The author obtained kinetic information by normalizing and differentiating the TGA curves with respect to time. The following equation provided the conversion $(a)$ for the reaction.

$$
\left.a=\left(m_{\text {initial }}-m_{\text {time }}\right)\right)\left(m_{\text {initial }}-m_{\text {final }}\right)
$$

In this equation $m$ represents the sample mass at the given time. knowing the conversion and its rate of change with time, one can easily calculate the rate constants for decomposition by standard regression technique [13].

In the DSC (differential scanning calorimetry) experiment, the author placed about 4 to $5 \mathrm{mg}$ of grounded sample in gold pans and put in the DuPont 2100 DSC thermal equipment. Notice that the use of gold pan will not influence the results because gold will react with neither the sample nor the atmosphere. The analysis heated the sample to $500{ }^{\circ} \mathrm{C}$ at a rate of $10{ }^{\circ} \mathrm{C} / \mathrm{min}$ under an argon atmosphere. Use of argon gas provided an anti-oxidant atmosphere that efficiently displaced the lighter air. The analysis compared the heat evolution of the sample to that of an empty gold cup used as a reference. Heat evolution appears as peaks in the resulting DSC spectra. Peaks pointing up (north) show exothermic behavior indicative of sample heat loss while peaks pointing down (south) represent endothermic behavior. Examples of processes giving rise to exothermic peaks include organic oxidation and hydrogenation of unsaturated molecules. The shape of the endothermic or exothermic peak provides information about the rate of the reaction.

Two accepted analytical methods exist to analyze weight loss in the TGA experiment or peak shape in the DSC experiment: differential and integral techniques. In the integral technique, one does not need to differentiate data and, therefore, avoids this source of errors. However, the integral technique requires an analytical relationship between conversion and time (or, in this case, temperature). If one decides to vary the heating rate using this method, the method also requires determination of an equipment calibration factor for use in calculating the activation energy [13]. The author elected to use the differential technique to avoid the uncertainty in the equipment calibration factor. In the differential technique, one assumes a generic kinetic function adequately represents the data and obtains kinetic parameters such as the rate constants of the kinetic analytical function as shown below.

$$
d a / d t=k \times[f(a)]^{n}
$$

In this equation, $a$ represents the conversion, $k$ represents the rate constant, $t$ indicates time, $n$ the exponential factor and $f(a)$ an analytical function of conversion. In the case of the decomposition of solids, $f(a)$ takes one of the following three forms [14].

$a^{n},(1-a)$ or $\ln (1-a)$ 
Through standard regression analysis, one determines the analytical form that best fits the data based on the correlation factor. First, the author determined the conversion at a temperature as the ratio of the partial weight loss at that temperature by the total weight loss for the given reaction. (The evaluation ignores the weight loss associated with the evaporation of water from the sample.) The rate of change of conversion at a given temperature comes directly from the ratio of the rate of change of conversion by the total weight as shown in the following equation.

$-\partial a / \partial t=(\partial m / \partial t) /\left(m_{\text {initial }}-m_{\text {final }}\right)$

The analytical relationship Ln $(1-a)$ correlated best with the current data. (See appendix 1 for a sample calculation.)

Most frequently, analyses contain many peaks due to the many reactions or phase transitions that occur in the sample during heating. In the case of the phenylborate compounds, one might expect distinct peaks from the decomposition of phenylboronic acid (1PB), diphenylborinic acid (2PB), triphenylborane (3PB), and sodium tetraphenylborate (4PB). The overall effective kinetic rate expression from a sample composed of many different decomposing components takes one of the following two mathematical forms [15].

$$
d a / d t=\sum_{i} d a_{i} / d t \times \%_{i}
$$

or

$d a / d t=\sum\left[\frac{\%_{i}}{d a_{i} / d t}\right]^{-1}$

In these expressions, the term $z_{i}$ represent weight percentage of the species $i$ reacted. The author used the first formula to compute the overall rate of benzene production in the solid waste because it reflects a mass balance for the production of benzene from all sources. This rate expression allows calculation of the net benzene production.

\section{RESULTS AND DISCUSSION}

\section{Effects of Salt Solution on Phenylborate Decomposition}

The author conducted thermal experiments on mixtures of the reagent phenylborate compound with a salt solution. The mixtures used the composition given in Table 2. The compositions come from analysis of the synthesized solution using high pressure liquid chromatography.

\begin{tabular}{llllll}
\hline Table 2. Compositions & used for salt-phenyl borate solutions. \\
\hline & LPB & 2PB & 3PB & NaTPB & $\begin{array}{c}\text { Composite } \\
\text { Mixture }\end{array}$ \\
\hline 1PB & $12698 \mathrm{mg} / \mathrm{L}$ & 0 & 0 & 0 & $1808 \mathrm{mg} / \mathrm{L}$ \\
2PB & 0 & $10433 \mathrm{mg} / \mathrm{L}$ & 0 & 0 & $466 \mathrm{mg} / \mathrm{L}$ \\
3PB & 0 & 0 & $1112 \mathrm{mg} / \mathrm{L}$ & 0 & $348 \mathrm{mg} / \mathrm{L}$ \\
NaTPB & 0 & 0 & 0 & $543 \mathrm{mg} / \mathrm{L}$ & $47 \mathrm{mg} / \mathrm{L}^{*}$ \\
Salt & Balance & Balance & Balance & Balance & Balance \\
\hline
\end{tabular}


* This value reflects liquid component only and does not include solids present as the potassium salt. The synthesis added sufficient NaTPB to reach a bulk concentration of $600 \mathrm{mg} / \mathrm{L}$.

Figures 1-4 contain the DSC spectra for the individual phenylborate compounds dissolved in the salt solution of Table 1 . For the experiment denoted as diphenylborinic acid (e.g., Figure 2), the researchers added the ethanolamine adduct to the solution. The triphenylborane material came from a nominal 9 wt $\%$ hydroxide adduct in $0.1 \mathrm{M}$ sodium hydroxide solution. This stock solution also contained trace quantities of the mono and diphenyl species as partial decomposition products.

Dried salt solutions containing phenylboronic acid showed an endothermic peak near $180^{\circ} \mathrm{C}$ (see Figure 1) while samples containing diphenylborinic acid showed an endothermic peak also near $180^{\circ} \mathrm{C}$ and an exothermic peak near $250^{\circ} \mathrm{C}$ (see Fig. 2). The molecular identification of the small exothermic peaks near 250 and $300^{\circ} \mathrm{C}$ remains unknown at this time. These peaks do not appear characterisitc of the phennylborate compounds and may represent either other impurities or baseline drifts of the equipment. However, their relatively small concentration will not affect the kinetic calculations. Researchers speculate that the exothermic peak results from oxidation of the ethanolamine fragment in the sample with residual oxygen in the atmosphere. Samples containing $3 \mathrm{~PB}$, as shown in Figure 3, showed a broad peak near $280^{\circ} \mathrm{C}$ with peaks below $210^{\circ} \mathrm{C}$ not identified. The sample containing NaTPB proved too wet during the writing of this report to provide meaningful spectra. However, the decomposition temperature range for NaTPB sample lies between $350{ }^{\circ} \mathrm{C}$ and $400{ }^{\circ} \mathrm{C}$ (figure not shown) well above the decomposition range of other phenylborates.

The sample containing the mixture of Table 2 showed endotherms near 225 ${ }^{\circ} \mathrm{C}$ characteristic of the $1 \mathrm{~PB}$ and $2 \mathrm{~PB}$ decomposition and another broad endotherm above $400{ }^{\circ} \mathrm{C}$ due to NaTPB decomposition (see Figure 4). The broad shoulder near $250^{\circ} \mathrm{C}$ is due to $\mathrm{B}(\mathrm{OH})_{3}$ decomposition. [16]. The peak positions shift to higher temperatures probably results from a network formation (hydrogen bonding for example) deriving from

interactions with neighboring hydroxides. Similarly, peaks for mixtures with two compounds that show reaction at nearly equal temperatures may also drift to higher temperatures in the spectra for the mixture. In this case, the center of gravity of two nearby peaks exists between the peaks. Figure 4 -- depicting the DSC profile of the NaTPB, 3PB, 2PB and $1 P B$-- does not completely illustrate the entire peak above $400^{\circ} \mathrm{C}$ because the experiment terminated at that time.

Except for the dried salts containing $1 \mathrm{~PB}$ and $2 \mathrm{~PB}$, the steady increase in decomposition temperature of the phenylborates with increasing number of phenyl molecules on the boron atom agrees with theoretical

predictions on the decomposition of phenylborates [16]. These peak positions agree relatively well with temperatures where weight losses occurred in the thermogravimetric data (TGA) of these solutions (see Figures 5, 6, 7, and 8). Looking at the TGA figures, a weight loss of 1.58 to 38 results from decomposition at the respective temperatures. Consider that drying one liter of salt solution containing phenylborates will yield approximately 200 grams of solid (neglecting mass gain for hydroxylates). Out of that 200 grams, 10 grams or 5 wt 8 represents the phenylborates. If benzene forms due to phenylborate decomposition, then the phenylborate weight loss would measure 25 to $49 \%$. Hence, the theoretical weight loss due phenylborate decomposition ranges from 1.25 
to 2.458 in the salt solutions, based upon the gravimetric results of this study.

Decomposition Rate of Phenylborate Containing Salt Solutions

The author used the TGA data to calculate kinetic parameters for the decomposition of the phenylborate solids (see Figures 9, 10, 11, and 12). Table 3 provides kinetic parameters obtained by the method described in the experimental section of this report.

Table 3. Kinetic parameters of the phenylborates in dried solids from waste solution (TGA)

\begin{tabular}{llll}
\hline SAMPLE & $\begin{array}{c}\text { E (activation energy, } \\
\mathrm{kJ} / \text { mole K) }\end{array}$ & $\begin{array}{c}\text { A(pre-exponential factor, } \\
\text { per minute) }\end{array}$ & $\mathrm{n}$ \\
1PB & 200.626 & $9.13 \mathrm{E} 20$ & 1.75 \\
$2 \mathrm{~PB}$ & 90.698 & $2.59 \mathrm{E} 10$ & 1.7 \\
3PB & 89.967 & $3.00 \mathrm{E} 08$ & 1.7 \\
& & & 1.85 \\
\hline
\end{tabular}

To test the accuracy of the TGA technique as well as the time response of the gravimetric equipment, the researcher conducted a TGA experiment on a calcium carbonate sample with known decomposition rate [17]. The activation energy and pre-exponential factor measured $176.9 \mathrm{~kJ} / \mathrm{mole}$ and 3.47 E8 per minute, respectively, compared to published values of 190 $\mathrm{kJ} / \mathrm{mole}$ and $6 \mathrm{E} 8$ per minute. The kinetic results agree reasonably well with the published data given the wide uncertainty for the kinetics of the calcium carbonate system. Therefore, the kinetic data from the TGA determinations provide reliable values.

The author examined reproducibility by analyzing the decomposition behavior of two samples with the same composition but different water amount. The results indicated a maximum of $3 \%$ error in the decomposition kinetics.

For the phenylborate analyses, the sources of error associated with computing kinetic parameters arise mainly from the measured mass of the sample and computation of the conversion from the TGA data. Analysis of an instrument temperature versus time and calibrated weight measurements indicate that instrumental sources of errors such as heating rate and weight balance appeared negligible. (Fluctuations no greater than 0.58 occurred for these parameters). The temperature in the equipment may 
prove in error by about $4{ }^{\circ} \mathrm{C}$ as determined from the onset of calcium carbonate decomposition (i.e., $576{ }^{\circ} \mathrm{C}$ compared to the literature value of $580^{\circ} \mathrm{C}$ at a heating rate of $10^{\circ} \mathrm{C}$ ). The propagation of errors in this experiment gave errors in conversion of $+/-0.003$ and $+/-0.0004$ in the calculation of derivatives. These errors in turn give uncertainties of $+/-68$ Joules for the activation energy and +/- 108 for the preexponential factor. The variation in the derived rate constant then measures about 28 given the variations in these kinetic parameters. author computed these errors by taking the square root of the sums of square of the individual sources of errors and made no attempt to calculate the limits of detection for the thermal equipment. However, errors are higher when the rate constant are computed from the confident limits of the fitting curve. Appendix 4 contains details of the estimate of the uncertainties (in percent) in the rate constants.

Although the technique appears precise, many potential sources of error exist in evaluating kinetic parameters. For example, a change of mechanism during decomposition will give erroneous answers. The analyst must carefully select a range of data not confounded by other mechanisms because different data ranges from the same decomposition curve may yield different kinetic parameters. A careful analysis always differentiates data with respect to temperature to examine areas where a single decomposition mechanism occurs.

The author estimated the overall decomposition rate for mixtures by the summation of the decomposition rates from the individual phenylborates. For example, Table 4 shows the rate for a mixture that represents a bounding composition for Tank $48 \mathrm{H}$ for the time period of interest [7] . The mixture contains $850 \mathrm{mg} / \mathrm{L}$ of $1 \mathrm{~PB}, 4500 \mathrm{mg} / \mathrm{L}$ of $2 \mathrm{~PB}, 6000 \mathrm{mg} / \mathrm{L}$ of $3 \mathrm{~PB}$ and $47 \mathrm{mg} / \mathrm{L}$ of NaTPB (i.e., the composition of Table 1). Figure 13 provides the estimated benzene generation rate for dried solids from one liter of solution taken from Tank $48 \mathrm{H}$ during the time period of greatest interest.

\begin{tabular}{ll}
\hline Table 4. Weight percent loss of solids per mass of dried salts per year. \\
\hline $\mathrm{T}\left({ }^{\circ} \mathrm{C}\right)$ & \multicolumn{1}{c}{ (TGA) } \\
\hline 25 & 0.392 wt 8 per year \\
50 & 6.73 wt 8 per year \\
60 & 18.55 wt 8 per year \\
\hline
\end{tabular}

The decomposition rate at $25^{\circ} \mathrm{C}$ in Table 4 measures roughly a factor of two lower than the values estimated in previous work for vendor supplied NaTPB solids [3]. The lower value may result from the lack of metal catalyst (i.e., copper) in this study. Finally, Table 5 lists the rate constant for each phenylborate component as a function of temperature.

Table 5. Fraction of solids lost per phenylborate compound per day as a function of temperature for each compound.

Temperature

\begin{tabular}{|c|c|c|c|c|}
\hline & 1PB & $2 \mathrm{~PB}$ & 3PB & NaTPB \\
\hline 25 & $8.53 \mathrm{E}-13$ & 0.002823 & 4.962E-05 & $8.52 \mathrm{E}-121$ \\
\hline 30 & $3.33 E-12$ & 0.005172 & 0.0000903 & $4.164 \mathrm{E}-117$ \\
\hline 40 & $4.467 \mathrm{E}-11$ & 0.01634 & 0.0002827 & 4.4E-110 \\
\hline 50 & $5.097 \mathrm{E}-10$ & 0.04807 & 0.0008248 & $1.71 \mathrm{E}-103$ \\
\hline 60 & $5.024 \mathrm{E}-09$ & 0.13254 & 0.002255 & $2.667 \mathrm{E}-97$ \\
\hline
\end{tabular}




\section{Conclusions}

Solid waste Engineering identified concerns about the benzene generation from decomposition of phenylborate in solid waste originating from the In-Tank Precipitation facility. The study measured decomposition rates of solid residues collected by drying salt solutions containing phenylborate compounds and of the pure reagents.

The results indicate that solids obtained by drying alkaline solutions that contained the phenylborate compounds decompose by releasing benzene. The data showed no evidence of interaction between the different phenylborate components during decomposition. The measured decomposition rate constants for the composite solids agree reasonably with previously published results [2-4] for NaTPB solids stored at a vendor location.

The rate expressions, tables, and figures of this report allow estimation of the benzene generation rate for wastes taken from the InTank Precipitation facility at specific times. The report provides an approximate uncertainty for those estimates.

This study did not allow extensive replication of the data and only evaluated a limited composition range. If analysis of existing waste containers by this method provides less than an order of magnitude margin, additional studies seem prudent. Such studies would, for example, include a broader range of conditions (i.e., mixture compositions and presence of metals), examination of benzene generation during drying, and add replicates for existing data.

\section{ACKNOWLEDGEMENTS}

The author gratefully acknowledges the assistance of Mark Barnes in performing the experiments and providing a salt solution for this study. Reid Peterson provided guidance on the range of compositions expected in material within Tank $48 \mathrm{H}$ for the time period of interest. Doug Walker provided assistance in obtaining materials for the thermal studies. Tom White of the Analytical Development Section of SRTC provided chemical analyses. Also the author thanks Bill Wilmarth, David Hobbs, and Sam Fink for technical guidance.

\section{REFERENCES}

1. P. Dunbar, Task Request, 98-TTR-0003, November 24, 1998.

2. M. J. Barnes, "Stability of Spray-Dried Sodium Tetraphenylborate (U), " WSRC-RP-94-774, August 5, 1994.

3. M. J. Barnes, "Decomposition of Sodium Tetraphenylborate (U)," WSRC-RP-90-465, May 10, 1990.

4. M. J. Barnes, "Sodium Tetraphenylborate Solution Stability - A Long Term Study (U)," WSRC-RP-92-786, June 11, 1992. 
5. J. P. Bibler, "TCLP Testing of Simulated Job Waste Containing NaTPB and KTPB (U)," WSRC-TR-95-0164, April 11, 1995.P. Dunbar, Task Request, 98-TTR-0003, November 24, 1998.

6. D. D. Walker, M. J. Barnes, C. I. Crawford, R. F. Swingle, R. A. Peterson, M. S. Hay, and S. D. Fink, "Decomposition of Tetraphenylborate in Tank 48H (U)," WSRC-TR-96-0113, Rev. 0, May $10,1996$.

7 R. A. Peterson, "1995/1996 Estimates of Phenylborate concentrations in Tank 48H, " WSRC-TR-99-00022, January, 1999.

S. S. Cooper, Analytical Chemistry, 29, 446 (1997).9 D. H. Geske, Journal of Physical Chemistry, 63, 1062 (1959).

10 J. L. R. Williams, J. C. Doty, P. J. Grisdale, T. H. Regan, and D. G. Borden, Chemical Communications, 109, (1967).

11 H. Nishida, N. Takada, M. Yoshimura, T. Sonoda, and H. Kobayashi,

12 Bulletin of the Chemical Society of Japan; 57, 2600 (1984).

13 P. J. Grisdale, J. L. R. Williams, M. E. Glogowski, and B. E. Babb, Journal of Organic Chemistry, 36, 544 (1971).

14 ASTM E 698, "Calibration Methods For Thermal Techniques".

15 J. Sestak, and G. Berggren, Thermochimica Acta, 3, 1 (1971).

16 M. E. Brown, D. Dollimore, and A. K. Galwey, "Comprehensive Chemical Kinetics," Chapter 22, in "Reactions in the Solid state," Elsevier, Amsterdam, 1980.

17 D. D. Dixon, N. G. Isern, P. D. Ellis, and M. K. Brown, "Research on Decomposition of Tetraphenylborate for ITP at SRS," in "Nuclear Magnetic Resonance, Electron Paramagnetic Resonance, and Molecular Modeling Studies of Sodium Tetraphenylborates Solutiosn at Pacific Northwest Laboratory," WSRC-TR-97-0110, by M. J. Barnes, C. L. Crawford, R. A. Peterson, and D. D. Walker, September 24, 1997.

18 P. J. Haines, "Thermal Methods of Analysis, Principles, Applications and Problems," Blackie Academic \& Professional, 1992. 


\section{APPENDIX 1: Kinetic calculations}

The following discussion provides more detailed information regarding the calculations of decomposition rates of phenylboronic acid (1PB) from TGA curves.

$$
\begin{aligned}
& \text { At } \mathrm{T}=210^{\circ} \mathrm{C}: \\
& a=\frac{(89.09-87.54)}{(89.09-87.07)} \quad\left(\text { at } 215^{\circ} \mathrm{C}\right) \\
& 1-a=0.2724
\end{aligned}
$$

One obtains the above values from the TGA curve as shown graphically in Figure 14. The rate of conversion comes from the following calculation.

$$
d a / d t=\frac{a b s(\beta \times d(w \%) / d T)}{(99.99-97.96)}
$$

In this expression $\beta$ is the heating rate $\left(10^{\circ} \mathrm{C} / \mathrm{min}\right)$. The author obtained the value $d(w$ of $/ d T$ from the $y$-value of the derivative thermogravimetric curve (DTGA) plot such as included in Figure 7. Also, one may obtain $d(w$ of)/dT by fitting the TGA curve with a reversed sigmodial function such as 


$$
\frac{w_{o} \%-w \%}{w_{o} \%-w_{f} \%}=\frac{1}{1+\exp \left(-\frac{\left(T-T_{\text {center }}\right)}{\text { width }}\right)}
$$

using a correlation coefficient criteria of 0.999 . The value $d(w q) / d T$ thus becomes

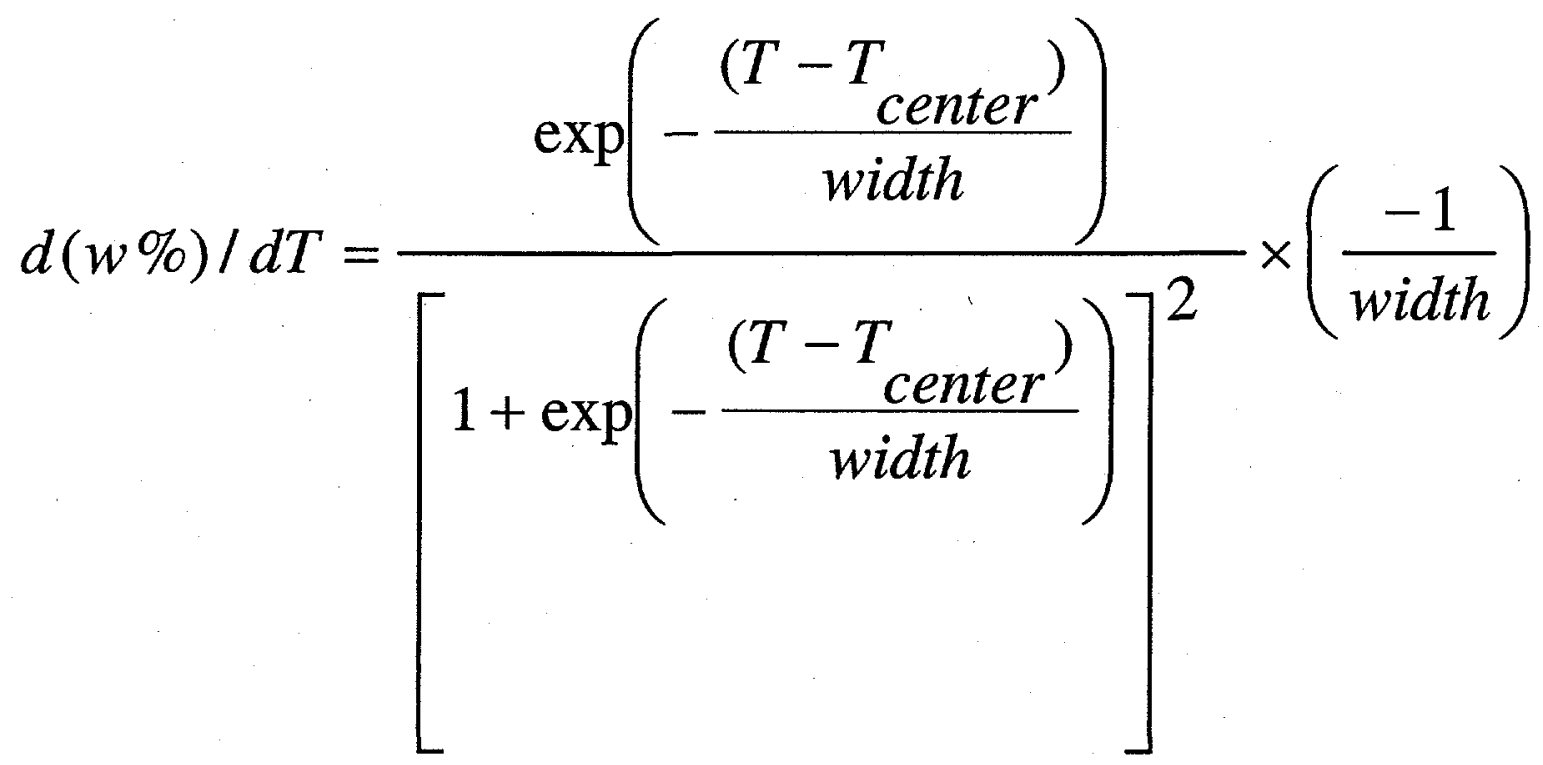

Table 6 contains kinetic calculations for phenylboronic acid in dried solids from solid waste. 
Table 6. Kinetic parameters for decomposition of phenylboronic acid in dried solids from alkaline solution.

\begin{tabular}{rrrrrrr}
$\mathrm{T}(\mathrm{C})$ & $1 / \mathrm{T}(1 / \mathrm{K})$ & \multicolumn{1}{c}{ WT\% } & \multicolumn{1}{c}{$\mathrm{A}$} & $1-\mathrm{A}$ & \multicolumn{1}{c}{$\mathrm{dA} / \mathrm{dT}$} & $\begin{array}{c}\text { Indadt- } \\
\text { Inf(a) }\end{array}$ \\
170 & 0.002257 & 88.67135 & 0.164327 & 0.835673 & 0.079607 & -0.65044 \\
172 & 0.002247 & 88.63825 & 0.180874 & 0.819126 & 0.085888 & -0.5405 \\
175 & 0.002232 & 88.58383 & 0.208083 & 0.791917 & 0.095525 & -0.37672 \\
180 & 0.002208 & 88.48027 & 0.259866 & 0.740134 & 0.111497 & -0.10715 \\
185 & 0.002183 & 88.36132 & 0.319339 & 0.680661 & 0.126005 & 0.157573 \\
187 & 0.002174 & 88.3099 & 0.34505 & 0.65495 & 0.131007 & 0.261963 \\
190 & 0.00216 & 88.22933 & 0.385337 & 0.614663 & 0.137303 & 0.416831 \\
192 & 0.002151 & 88.17373 & 0.413136 & 0.586864 & 0.140551 & 0.518889 \\
195 & 0.002137 & 88.08832 & 0.45584 & 0.54416 & 0.143795 & 0.670137 \\
197 & 0.002128 & 88.03057 & 0.484715 & 0.515285 & 0.14479 & 0.769722 \\
200 & 0.002114 & 87.94368 & 0.528159 & 0.471841 & 0.144465 & 0.917212 \\
205 & 0.002092 & 87.80137 & 0.599314 & 0.400686 & 0.139207 & 1.158027 \\
207 & 0.002083 & 87.74638 & 0.626809 & 0.373191 & 0.135603 & 1.252643 \\
210 & 0.00207 & 87.66697 & 0.666515 & 0.333485 & 0.128852 & 1.392809 \\
215 & 0.002049 & 87.54486 & 0.727568 & 0.272432 & 0.114904 & 1.622001 \\
220 & 0.002028 & 87.43777 & 0.781115 & 0.218885 & 0.099114 & 1.846204 \\
222 & 0.00202 & 87.39942 & 0.800291 & 0.199709 & 0.092651 & 1.934639 \\
225 & 0.002008 & 87.34671 & 0.826644 & 0.173356 & 0.083073 & 2.066098 \\
230 & 0.001988 & 87.2713 & 0.864348 & 0.135652 & 0.06797 & 2.282377 \\
235 & 0.001969 & 87.21021 & 0.894894 & 0.105106 & 0.054526 & 2.495694 \\
237 & 0.001961 & 87.18938 & 0.905311 & 0.094689 & 0.049694 & 2.580326 \\
240 & 0.001949 & 87.16159 & 0.919205 & 0.080795 & 0.043053 & 2.706634 \\
242 & 0.001942 & 87.14518 & 0.927408 & 0.072592 & 0.039027 & 2.790459 \\
245 & 0.001931 & 87.12344 & 0.938281 & 0.061719 & 0.033571 & 2.915695 \\
250 & 0.001912 & 87.09384 & 0.953082 & 0.046918 & 0.025922 & 3.123289 \\
255 & 0.001894 & 87.07106 & 0.964469 & 0.035531 & 0.019866 & 3.32975
\end{tabular}


APPENDIX 2 : Rate of decomposition calculations

The following discussion provides more detailed information regarding the decomposition of rates of diphenylborinic acid (2PB) as a function of temperature.

Table 3 lists the the activation energy and pre-exponential factor for the decomposition rate of $2 \mathrm{~PB}$ as:

$\mathrm{E}_{\mathrm{a}}=90698 \mathrm{~J} /$ mole and

$A=2.59 \times 10^{10}$ per minute, or $3.7296 \times 10^{13}$ per day.

Hence, the following expression gives the rate constant for 2PB decomposition per day.

$$
3.73 \times 10^{13} \times \exp \left(\frac{-90698}{8.314 \times T}\right)
$$

In this equation, $T$ represents the temperature in degree Kelvin.

One then determines the fraction of solids lost in benzene generation per phenylborate compound per day by the following expression.

$$
\left(\frac{\text { benzene yield } \%}{100}\right) \times k \times(n-1)
$$

Table 3 lists the value of $n$. The benzene yield equals the ratio of benzene generated in mass to the initial mass of phenylborate compound (see appendix 3).

For example at $43^{\circ} \mathrm{C}$, the decomposition rate for 2 PB becomes:

$$
3.73 \times 10^{13} \times \exp (-90698 /(8.314 *(43+273))=0.0379 \text { per day. }
$$

This gives a fraction of solid lost in benzene generation per phenylborate compound of:

$0.858 \times 0.0379$ per day $\times(1.7-1)=0.02276$ per day. 
APPENDIX 3: Benzene yields calculations and average decomposition rate expression.

The author computed the benzene yield for the four different phenylborate compounds as follows.

For sodiumtetraphenylborate:

$$
\mathrm{N}_{\mathrm{a}} \mathrm{B} \phi_{4} \Rightarrow 4 \phi \text { gives } 91.3 \% \text { benzene yield }(=100 \times 312 / 341.8) \text {. }
$$

In this expression, $\phi$ represents phenyl molecules on boron.

For triphenylborane decomposition:

$$
\left.\mathrm{B} \phi_{3} \Rightarrow 3 \phi \text { gives } 96.8 \% \text { benzene yield ( }=100 \times 234 / 241.8\right) \text {. }
$$

In the case of diphenylborinic acid decomposition:

$(\mathrm{OH}) \mathrm{B} \phi_{2} \Rightarrow 2 \phi$ gives $85.8 \%$ benzene yield $(=100 \times 156 / 181.8)$.

Finally, in the case of phenylborinic acid:

$(\mathrm{OH})_{2} \mathrm{~B} \phi \Rightarrow \phi$ gives $64 \%$ benzene yield $(=100 \times 78 / 121.8)$.

The average phenylborate decomposition rate comes from the following calculation.

$$
d a / d t=k \times(1-a)^{n}
$$

Integrating as a function of time gives the conversion as follows:

$$
(1-a)=[k \times t \times(1-n)+1]^{1 /(1-n)}
$$

In this expression, $t$ represents time.

The general average decomposition rate becomes:

$$
\langle d a / d t\rangle=\int_{0}^{T_{\text {final }}}(d a / d t) d t / T_{\text {final }}
$$


In this equation, $T_{\text {final }}$ (the end of the reaction) is given as:

$$
T_{\text {final }}=[k \times(n-1)]^{-1}
$$

Inserting the expression for $\mathrm{da} / \mathrm{dt}$ into the average decomposition rate expression gives:

$$
\langle d a / d t\rangle=k \times(n-1)
$$

The fraction of benzene generated per mass of phenylborate compound thus becomes:

$$
\text { (\%benzene yield }) \times k \times(n-1)
$$

The author used this expression to generate the entries in Table 5.

The fraction of benzene generated per initial mass of dried salt follows as:

(\% phenylcompound / salt $) \times(\%$ benzene/ phenylcompound $) \times k \times(n-1)$

The entries in Table 4 and the data in Figure 13 derived from the above expression. 
APPENDIX 4: Calculation of uncertainties in the rate constant as a function of temperature

Rate constant calculations of the $95 \%$ confident limits in the kinetic parameters yielded the values tabulated in Table 7 .

Table 7. Rate constant uncertainties (in percent) of the phenylborate compounds.

\begin{tabular}{|l|l|l|l|}
\hline TEMPERATURE & 1PB & 2PB & 3PB \\
\hline $25{ }^{\circ} \mathrm{C}$ & $+1-44 \%$ & $+1-49 \%$ & $+1-16 \%$ \\
\hline $40{ }^{\circ} \mathrm{C}$ & $+1-70 \%$ & $+1-36 \%$ & $+1-13.5 \%$ \\
\hline $60{ }^{\circ} \mathrm{C}$ & $+1-76 \%$ & $+1-32 \%$ & $+1-12.5 \%$ \\
\hline
\end{tabular}




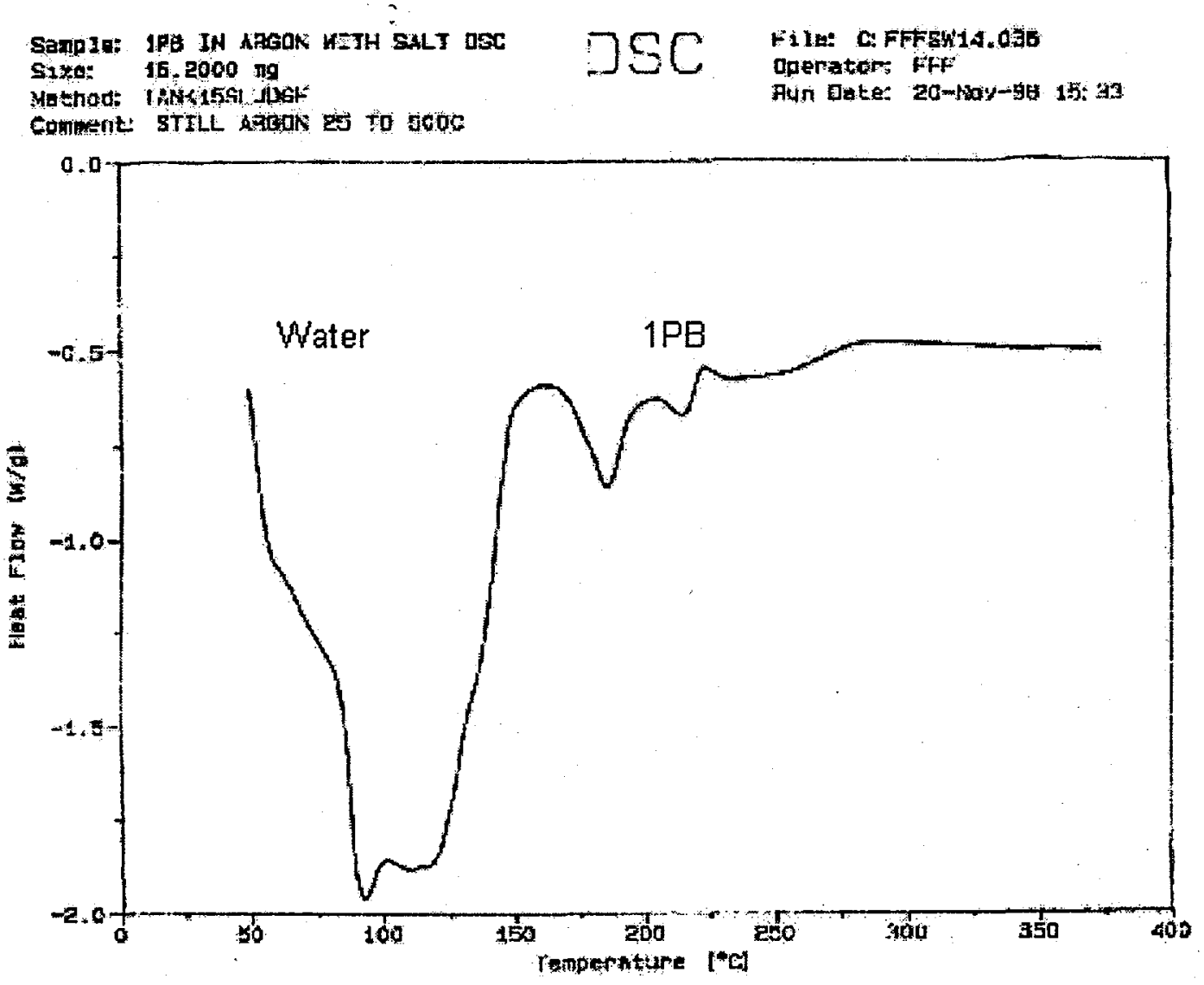

Fig. 1. Differential scanning calorimetric curve (DSC) of phenylboronic acid (1PB) in dried solids from waste solution. 


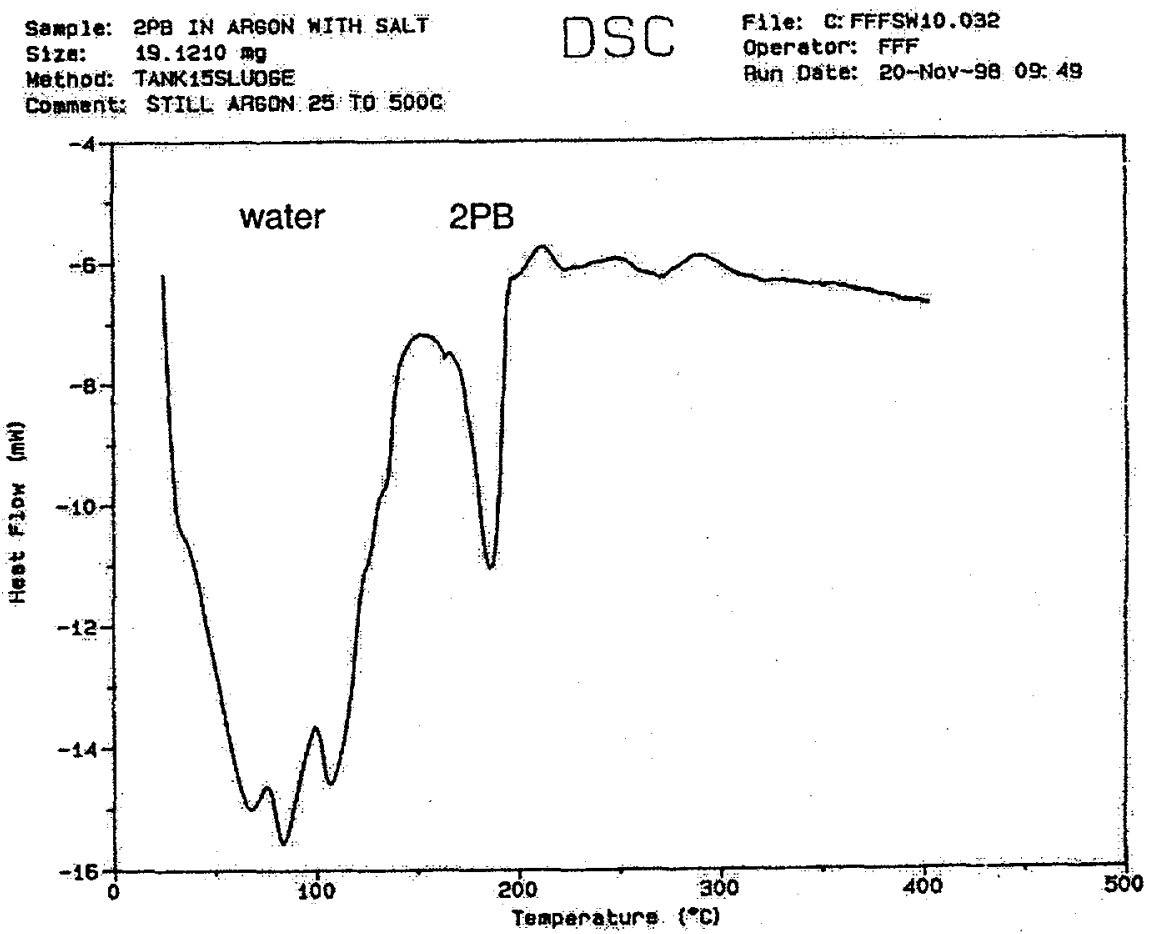

Fig. 2. Differential scanning calorimetry curve (DSC) of diphenylborinic acid (2PB) in dried solids from waste solution. 


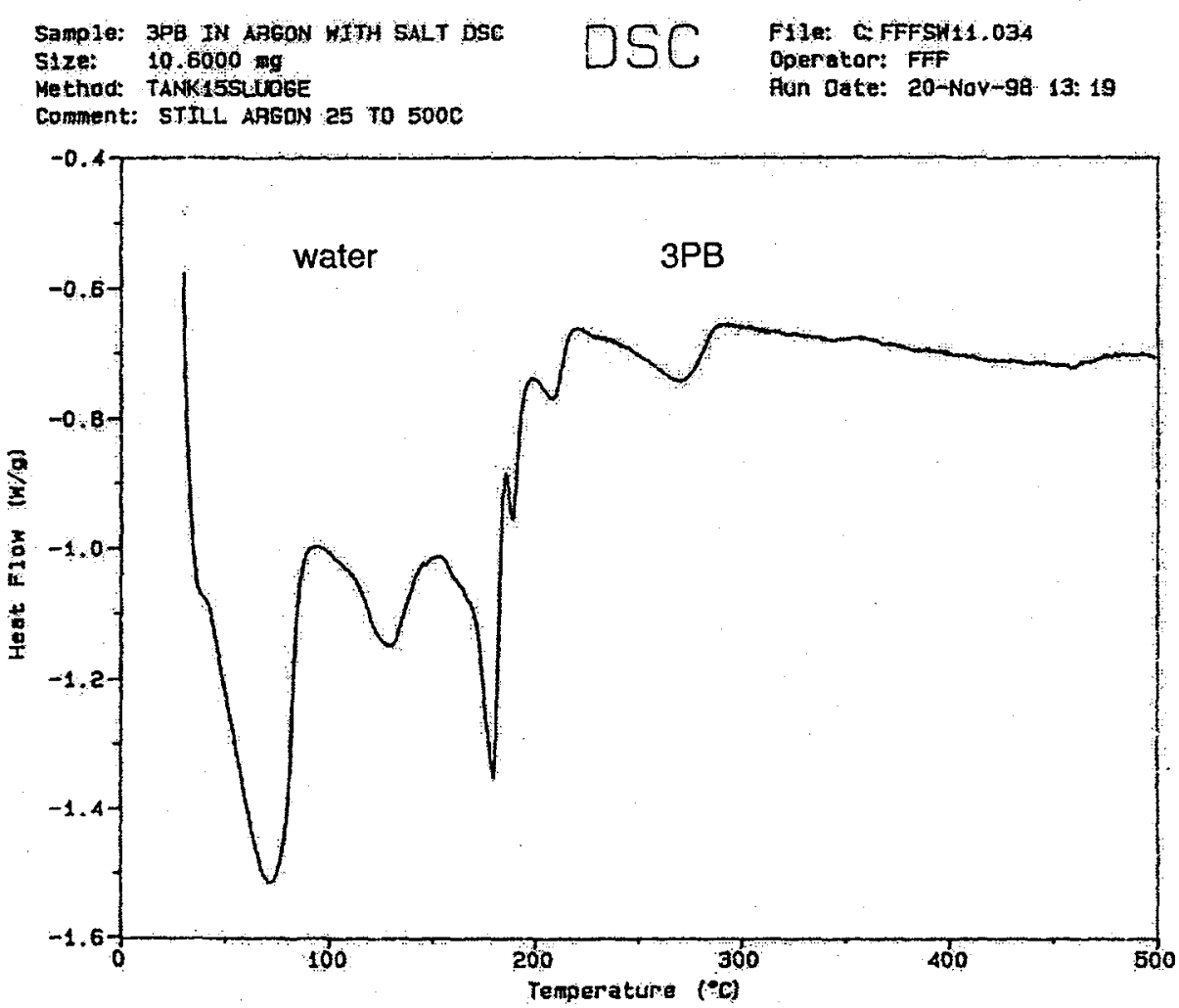

Fig. 3. Differential scanning calorimetry curve (DSC) of triphenylborane (3PB) in dried solids from waste solution. 


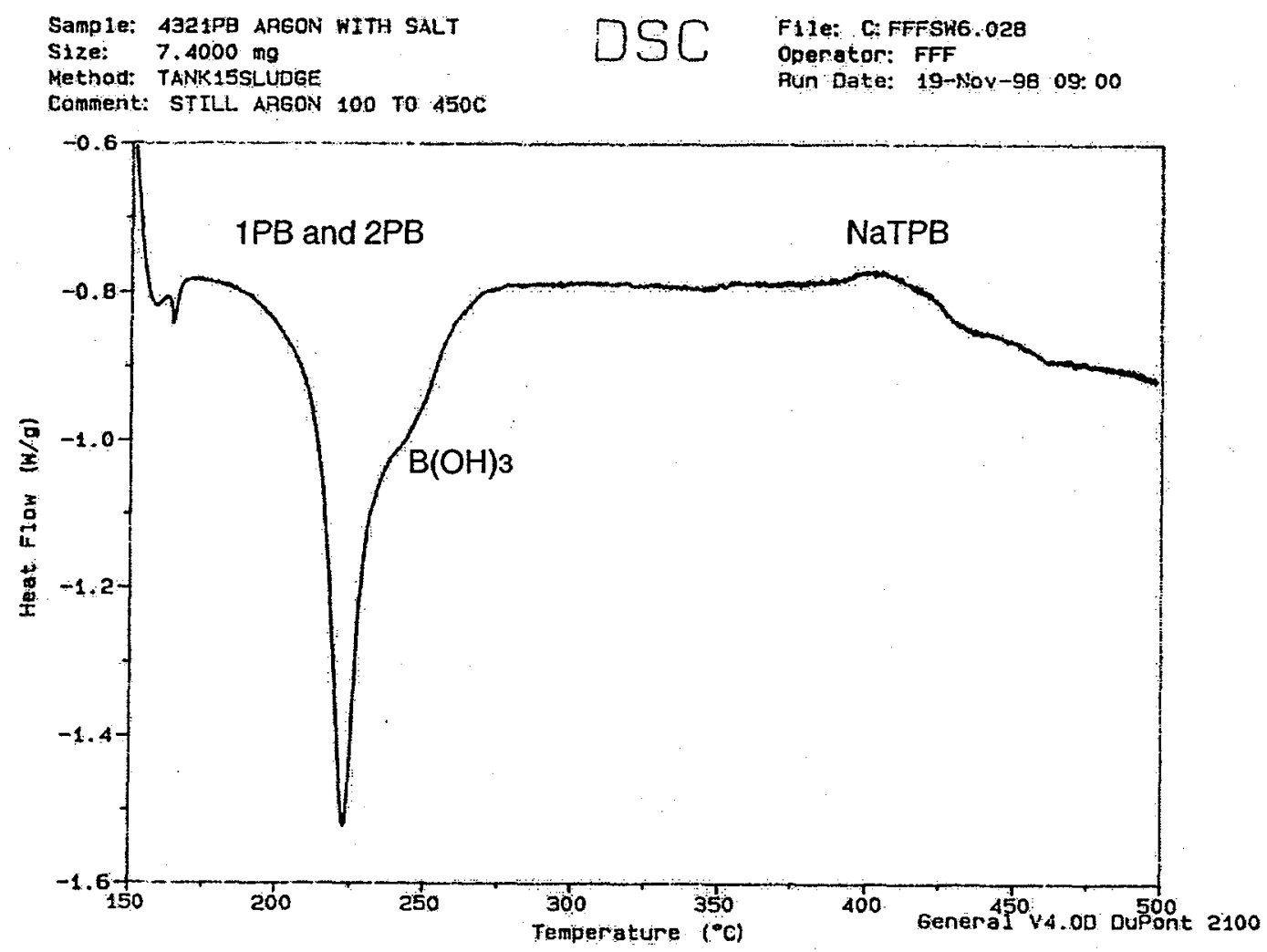

Fig. 4. Differential scanning calorimetry curve (DSC) of phenylboronic acid (1PB), diphenylborinic acid (2PB), Borinic acid and sodium tetraphenylborate (NaTPB) in dried solids from waste solution. 


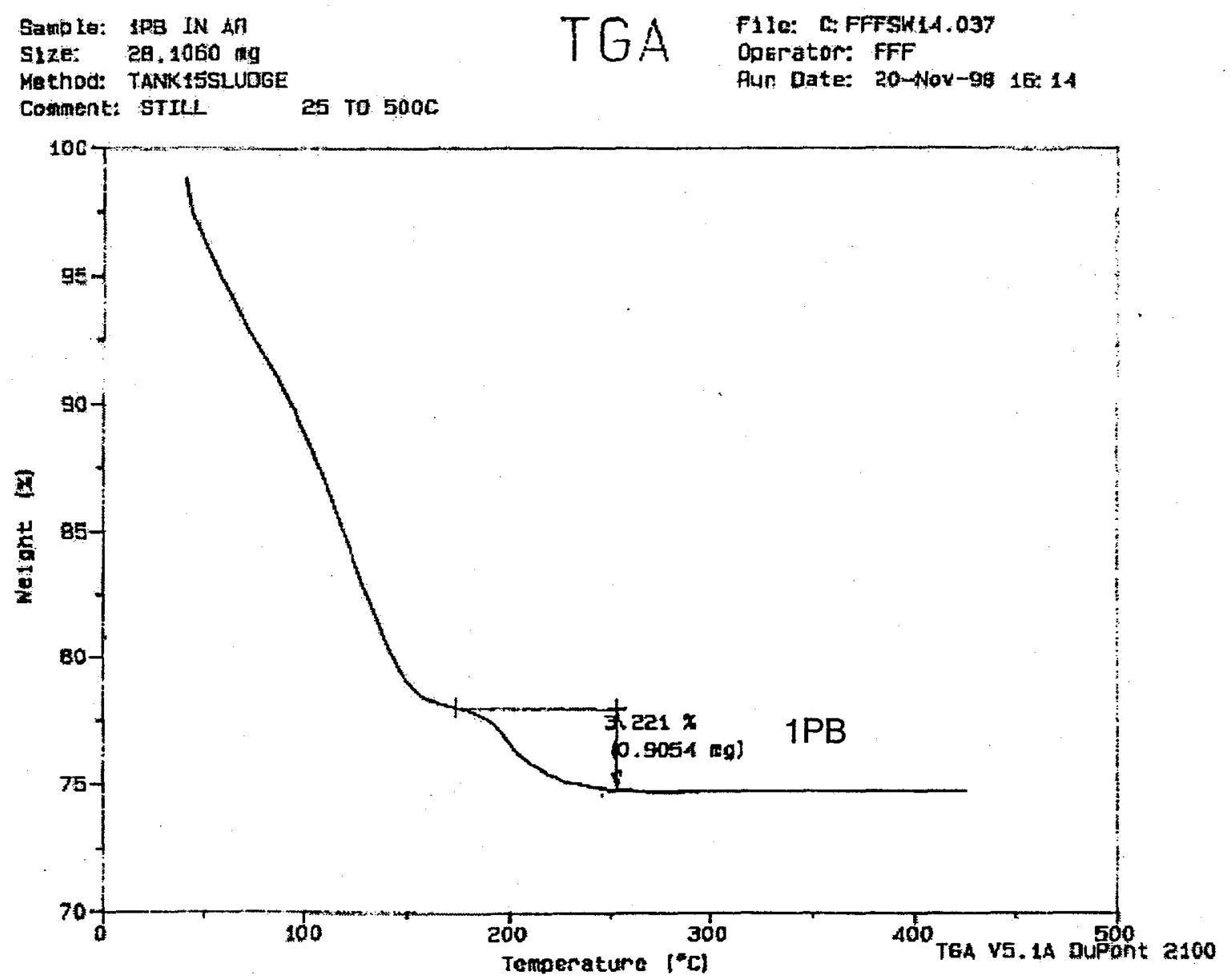

Fig. 5. Thermogravimetric Analysis (TGA) curve of phenylboronic acid (1PB) in dried solids fromwaste solution. 


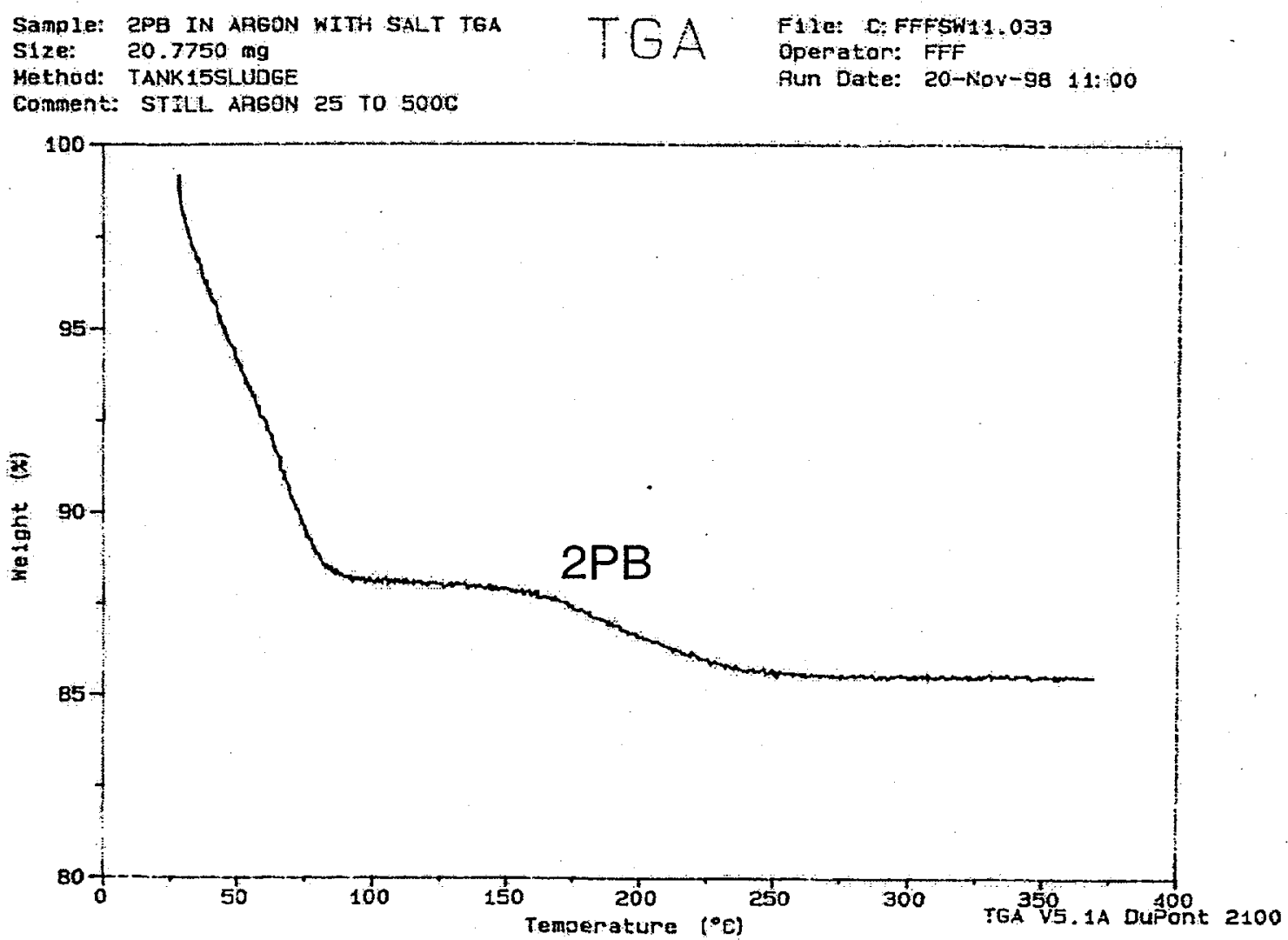

Fig. 6. Thermogravimetric analysis curve (TGA).curve of diphenylborinic acid (2PB) in dried salt solution. 


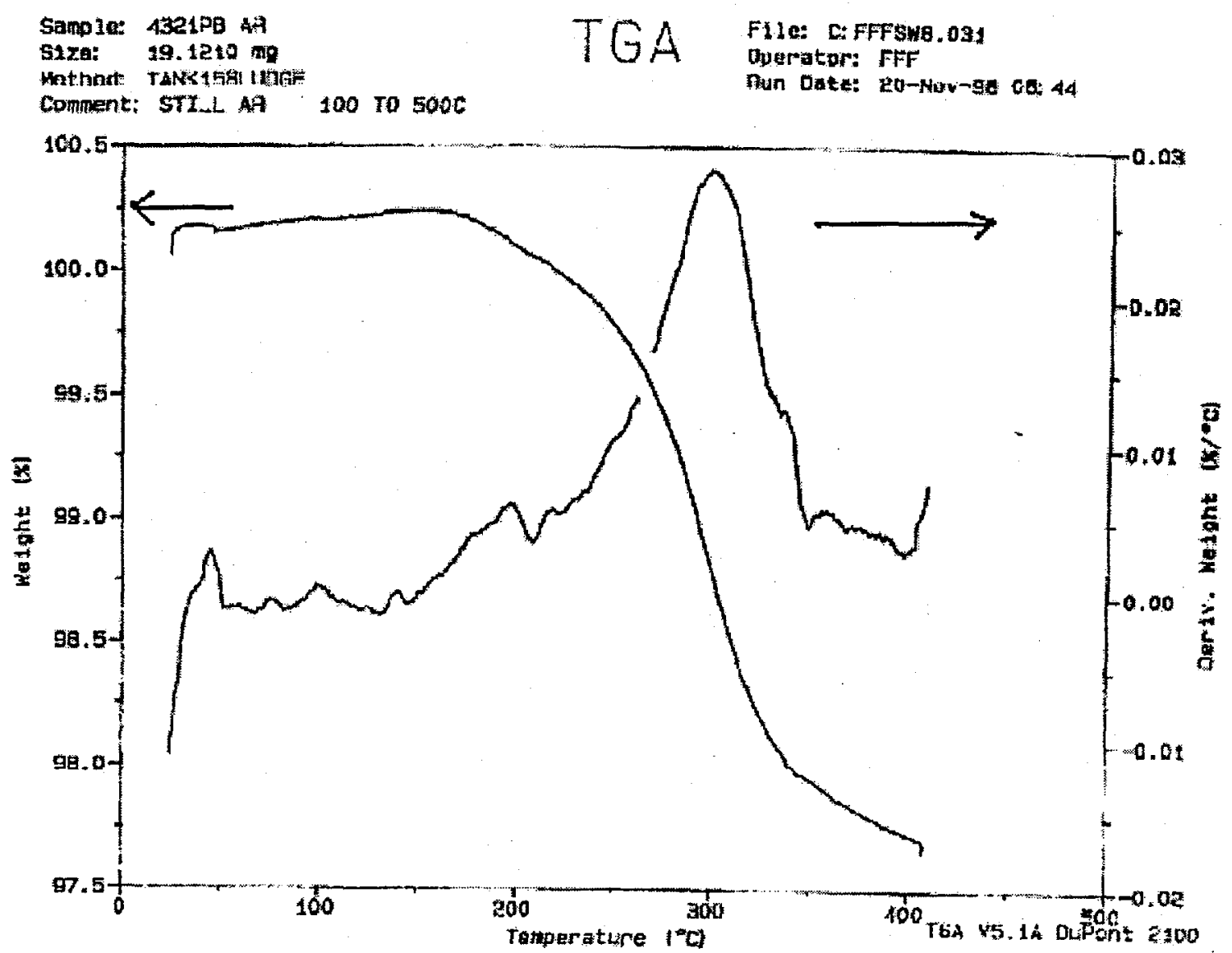

Fig. 7. Thermogravimetric analysis (TGA) curve of triphenylborane (3PB) in dried solids from waste solution. The figure also depicts the derivative of the weight loss profile. 


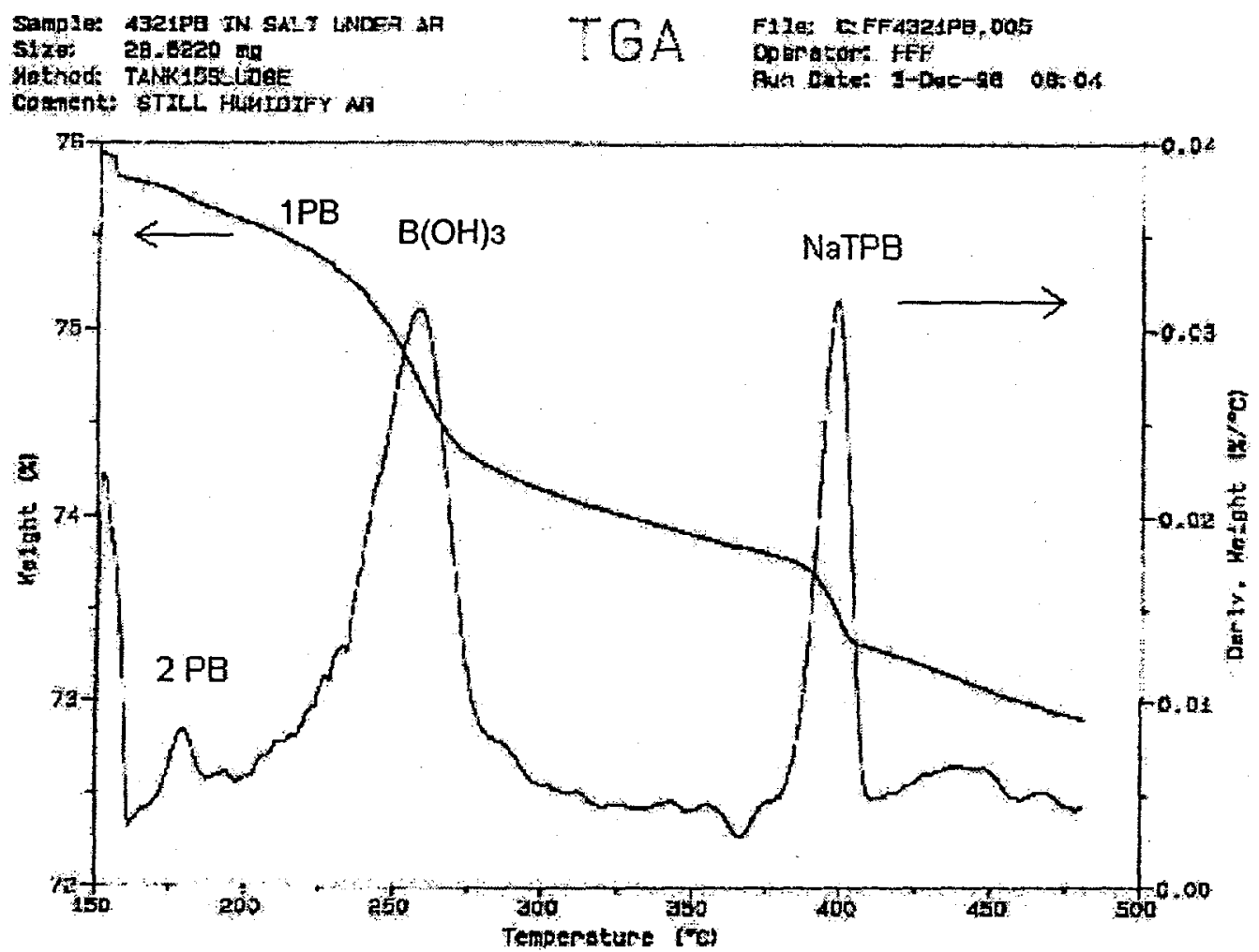

Fig. 8. Thermogravimetric analysis of a dried solids from waste solution containing phenylboronic acid (1PB), diphenylborinic acid (2PB), Borinic acid and sodium tetraphenylborate (NaTPB). The figure also depicts the derivative of the weight loss profile. 


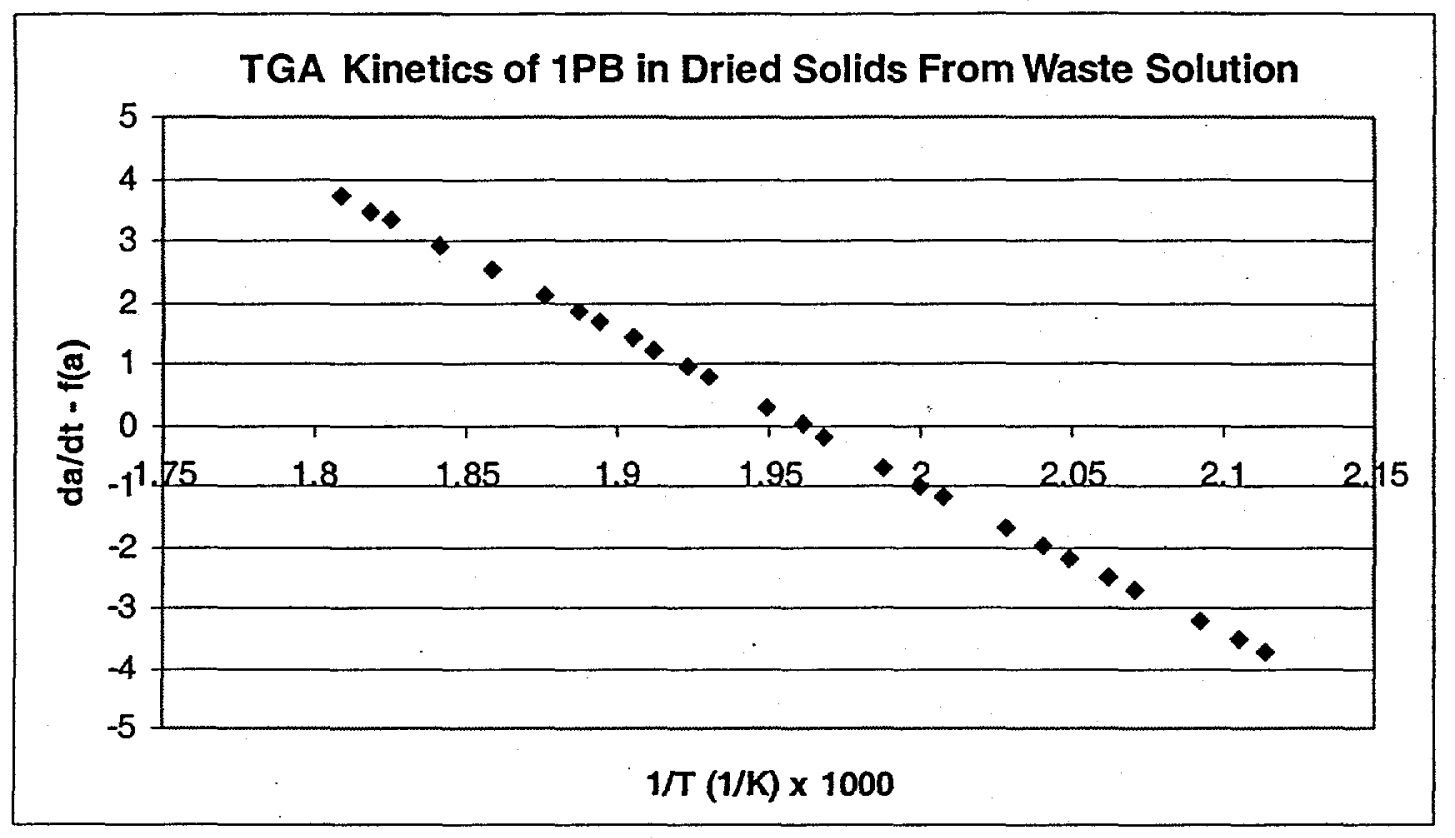

Fig. 9. Kinetic curve derived from the thermogravimetric analysis (TGA) curve of phenylboronic acid (1PB) in dried solids from waste solution. 


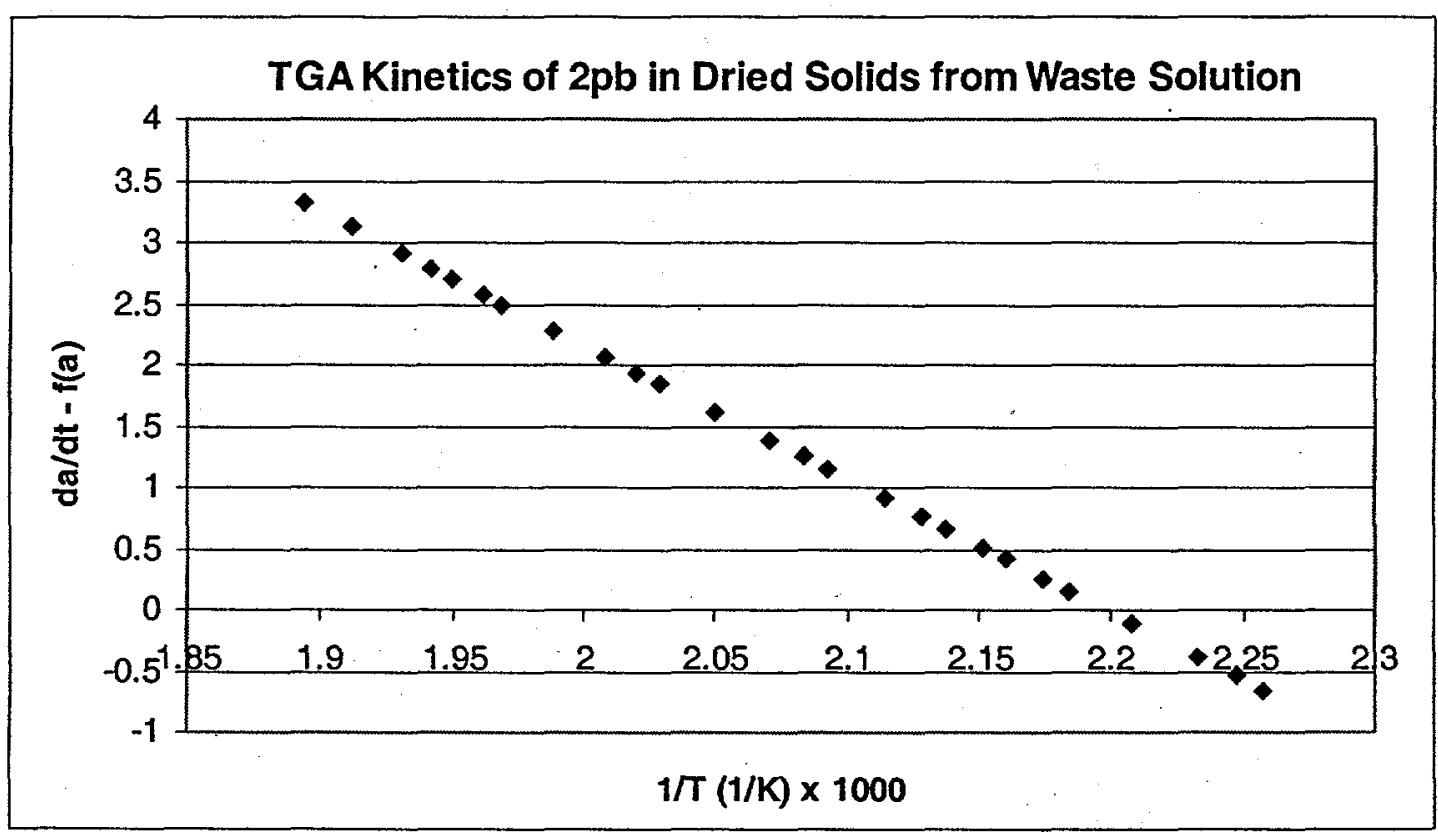

Fig. 10. Kinetic curve obtained from the thermogravimetric analysis (TGA) of diphenylborinic acid (2PB) in dried solids from waste solution. 


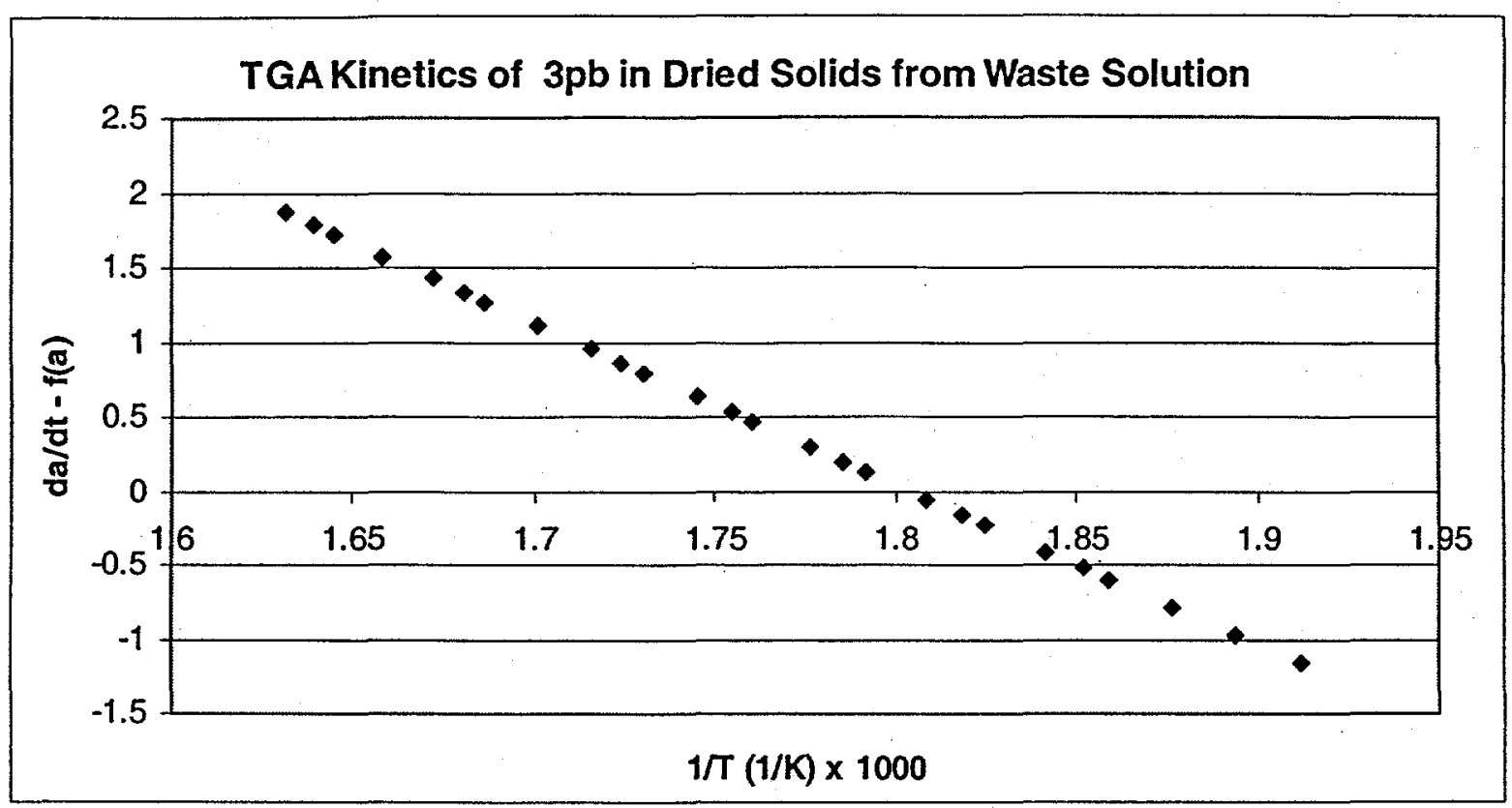

Fig. 11. Kinetic curve obtained from the thermogravimetric analysis (TGA) curve of triphenylborane (3PB) in dried solids from waste solution. 


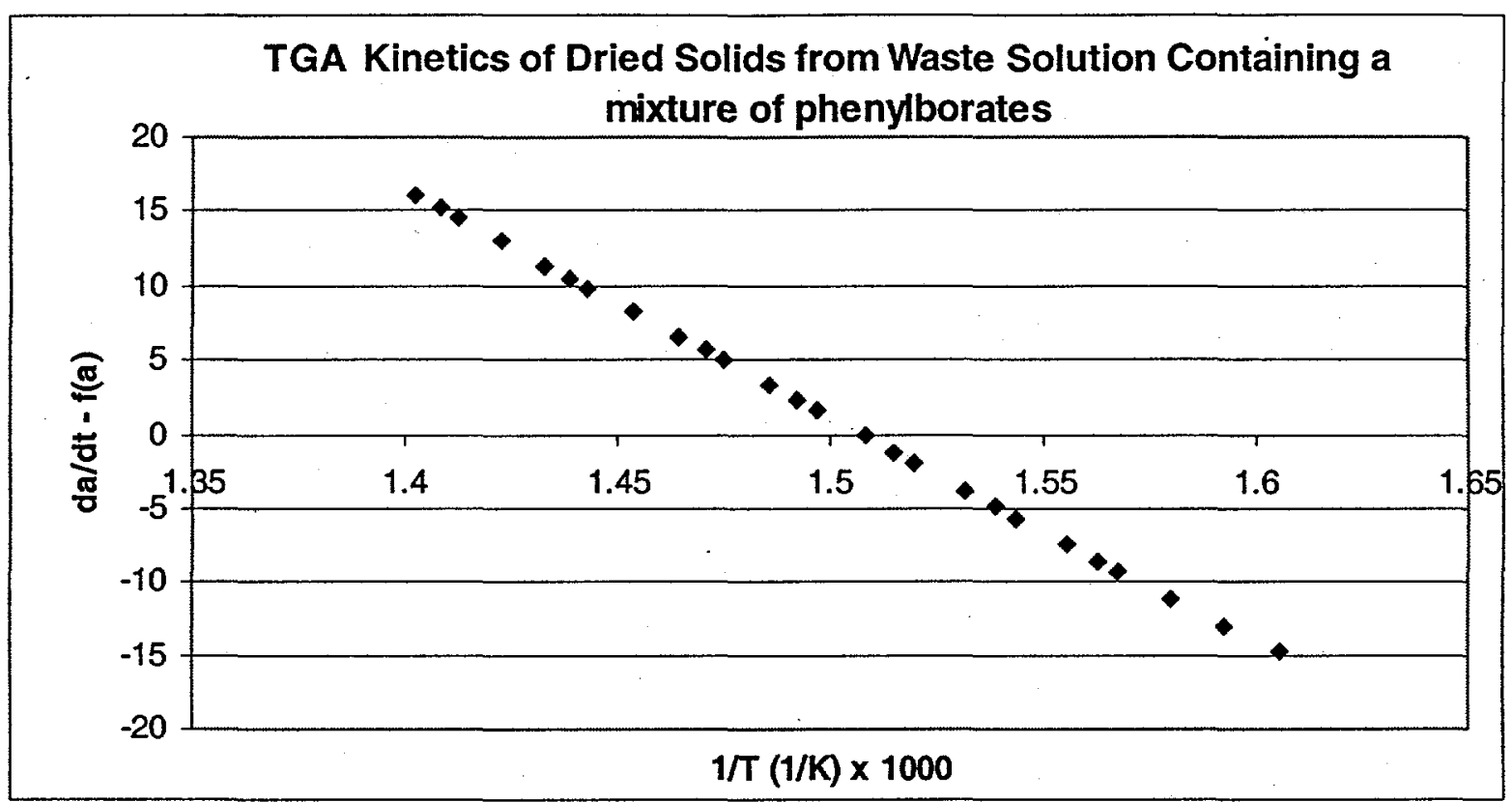

Fig. 12. Kinetic curve obtained from thermogravimetric analysis (TGA) curve of dried solids from waste solution containing a mixture of phenylborates. The data is from the sodium tetraphenylborate (NaTPB) decomposition $\left(400^{\circ} \mathrm{C}\right)$. 


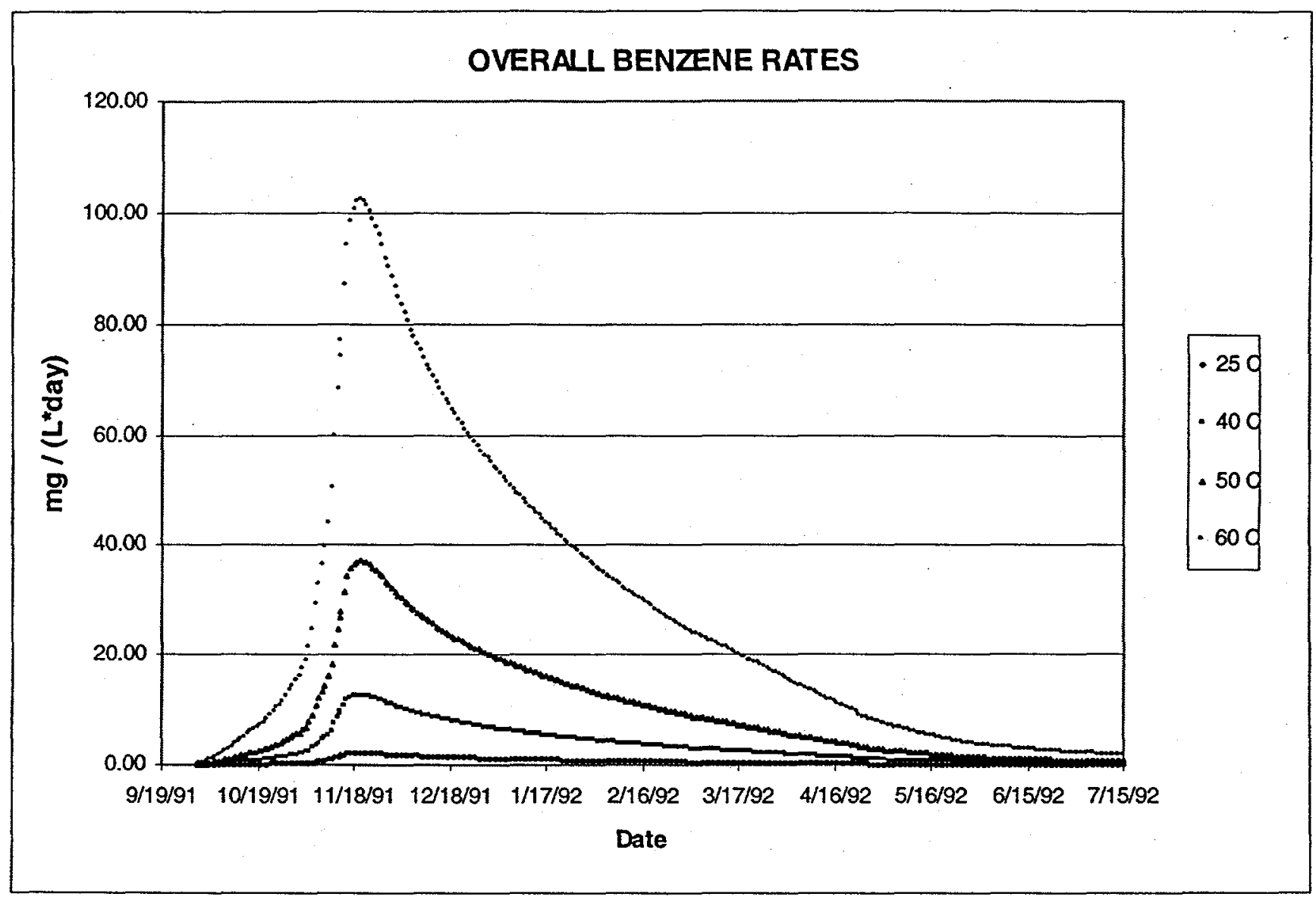

Fig. 13. Calculated benzene production rate from dried solids of waste solutions with Tank $48 \mathrm{H}$ composition as a function of temperature. 


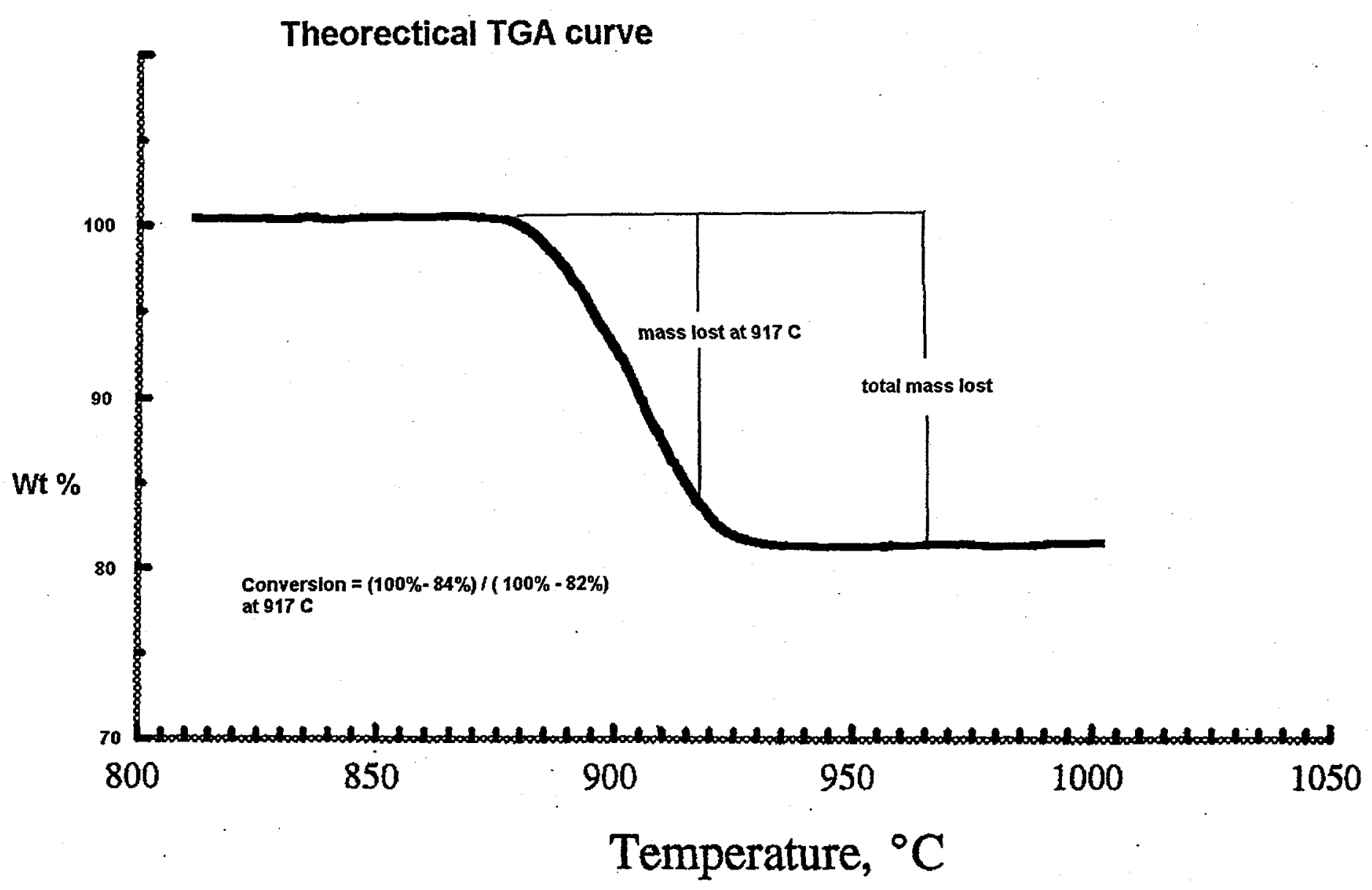

Fig.14. A simulated thermogravimetric analysis curve (TGA) showing a conversion calculation. 